\title{
Effect of Mechanical Vibration on Microstructure and Mechanical Properties of Gray Cast Iron in Lost Foam Casting
}

\author{
Kai Qiu ${ }^{1}{ }^{1}$ and Bota Xiao ${ }^{2}$ \\ ${ }^{1}$ School of Mechanical Engineering, Xijing University, Xi'an 710123, China \\ ${ }^{2}$ School of Materials Science and Engineering, Xi'an Jiaoton University, Xi'an 710048, China \\ Correspondence should be addressed to Kai Qiu; iandyouagain@sina.com
}

Received 6 May 2021; Accepted 18 August 2021; Published 7 September 2021

Academic Editor: Georgios I. Giannopoulos

Copyright ( $) 2021$ Kai Qiu and Bota Xiao. This is an open access article distributed under the Creative Commons Attribution License, which permits unrestricted use, distribution, and reproduction in any medium, provided the original work is properly cited.

\begin{abstract}
In order to reveal the effect of vibration solidification on microstructure and properties of gray cast iron in lost foam casting, Y-shaped HT100 gray cast iron was prepared by vibration lost foam casting, and the effect of amplitude on the microstructure and properties of gray cast iron was studied. The results showed that, with the increase in amplitude, the short and thin A-type flake graphite increases, and the austenite structure transforms from columnar to cellular. The hardness, tensile strength, and elongation of gray cast iron first increase and then decrease with the increase in amplitude. The appropriate amplitude in the process of Y-shaped HT100 gray cast iron by lost foam casting is $2 \mathrm{~mm}$, while the tensile strength and elongation of gray cast iron are the highest, with the values of $147.51 \mathrm{MPa}$ and $1.17 \%$, respectively. The change of mechanical properties of gray cast iron is mainly determined by the morphology and distribution of austenite in gray cast iron and A-type flake graphite.
\end{abstract}

\section{Introduction}

Casting is an important forming method of parts or blanks, especially suitable for the production of complex shape parts, which is favored by production enterprises [1]. However, the casting or blanks produced by casting have defects such as shrinkage cavity, shrinkage porosity, and coarse structure, which lead to poor performance [2]. In view of these problems, casting researchers and production personnel have carried out a lot of research work, aiming at refining the casting or blank structure and improving its mechanical properties [3]. Many methods of refining the casting structure have been proposed, such as increasing the undercooling, adding modifier, and applying vibration in the solidification process [4]. Among the three methods mentioned above, vibration solidification is a physical modification method, which is a method of grain refinement developed in the past 30 years [5-7].

Lost foam casting (LFC) is a near net forming method, which is suitable for the manufacture of castings with complex shape. It can be used for the production of engine box, machine bed, and other castings made of gray cast iron. Due to the introduction of foam mold in lost foam casting process, the casting temperature is too high, and at the same time, the lost foam casting adopts dry sand molding, which makes the cooling rate of the casting lower $[7,8]$. Therefore, the gray cast iron has the problems of coarse primary structure and low mechanical properties.

In order to solve the problem of coarse structure in lost foam casting, researchers put forward a good method to refine the grain size and improve the properties of castings by using the vibration compaction table of lost foam casting. Tian et al. [9] applied mechanical vibration to the solidification process of AZ91 alloy and found that mechanical vibration can obviously refine the microstructure of AZ91 alloy, and the composition of Al-Mn phase changes from $\mathrm{Al}_{32} \mathrm{Mn}_{25}$ to $\mathrm{Al}_{13} \mathrm{Mn}_{12}$ without vibration. When the exciting force is $1.5 \mathrm{kN}$, the tensile strength of AZ91 alloy is $27 \%$ higher than that of AZ91 alloy without vibration. When the excitation force is more than $1.5 \mathrm{kN}$, the strength of AZ91 alloy decreases. Jiang et al. $[10,11]$ found that the initial phase and eutectic silicon of aluminum alloy can be refined 
and the mechanical properties of the alloy can be improved by applying vibration during solidification. Xiao et al. [12] found that mechanical vibration during solidification of ductile iron can increase the number of graphite balls per unit area, change the morphology and distribution of ferrite and cementite in pearlite structure, and improve the mechanical properties of ductile iron. The results show that mechanical vibration can change the phase composition and phase distribution of the alloy, and the microstructure and properties of the casting vary greatly with the setting of vibration parameters.

Although the vibration lost foam casting can refine the casting structure and improve the casting performance, in the existing research reports, the research on vibration lost foam casting mainly focuses on aluminum alloy, magnesium alloy, and ductile iron $[13,14]$, while the research on vibration lost foam casting of gray iron is less. Gray cast iron is a multiphase structure composed of flake graphite, ferrite, and cementite, and the mechanical vibration during solidification of gray cast iron is bound to show a more complex structure transformation phenomenon. In order to reveal the effect of vibration solidification on the microstructure and properties of gray cast iron in lost foam casting, Y-shaped test blocks of HT100 were formed by mechanical vibration with different amplitudes in the process of LFC.

\section{Test Materials and Methods}

Scrap, cast iron, ferromanganese, carburizing agent, and 75 ferrosilicon are used as raw materials to smelt molten iron, and the smelting equipment is $1 \mathrm{~T}$ medium frequency induction furnace. During smelting, charge is added according to the designed composition; scrap, cast iron, and carburizing agent are added first, and then smelting is started. When the temperature rises to $1500^{\circ} \mathrm{C}$, prefurnace detection is carried out. The equipment used is YL-DA type multielement analyzer, and then carburizing agent, scrap, and ferromanganese and ferrosilicon are used to adjust the molten iron to the designed composition, and the designed alloy composition is shown in Table 1.

The molten iron was modified and poured with 75 ferrosilicon as modifier, and the amount of modifier was $1.4 \%$ of the mass of molten iron. The mechanical vibration parameters during pouring are as follows: the vibration direction is vertical vibration, the vibration frequency is $35 \mathrm{~Hz}$ (which has been optimized in the previous research of the research group), and the amplitude is $0 \mathrm{~mm}, 2 \mathrm{~mm}$, $3 \mathrm{~mm}$, and $4 \mathrm{~mm}$, respectively. The schematic diagram of the vibrating device by LFC is shown in Figure 1.

The morphology of graphite before corrosion and primary austenite after corrosion of gray cast iron was observed by Olympus-GX51 type optical microscope, the corrosion solution was $4 \%$ nitric acid alcohol solution, the length and content of flake graphite were studied by using the statistical analysis software of the optical microscope, six metallographic photos of each area were counted, and the average value was taken as the test result. The hardness was measured with HBE-3000 A-type Brinell hardness machine, the diameter of the ball was $10 \mathrm{~mm}$, the load was $1000 \mathrm{~kg}$, the
TABle 1: Chemical composition and content of HT100 (mass fraction, \%).

\begin{tabular}{lccccc}
\hline $\mathrm{C}$ & $\mathrm{Si}$ & $\mathrm{Mn}$ & $\mathrm{P}$ & $\mathrm{S}$ & $\mathrm{Fe}$ \\
\hline 3.46 & 2.52 & 0.47 & 0.011 & 0.02 & Bal. \\
\hline
\end{tabular}

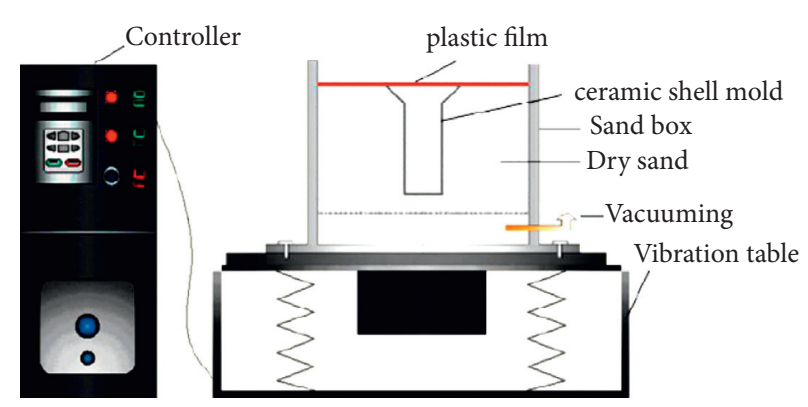

FIgURE 1: Schematic diagram of the vibrating device by LFC.

loading time was $15 \mathrm{~s}$, five points were measured for each sample, the maximum and minimum values were removed, and the average value of the remaining three data was taken as the final result. The mechanical properties of gray cast iron in vibration lost foam casting were measured by MTS-810 type tensile testing machine, the tensile test was carried out at room temperature, and the tensile speed was $1 \mathrm{~mm} / \mathrm{min}$. The size of tensile specimen is shown in reference [12]. Finally, the fracture morphology was observed by the FEI Quanta 200 type environmental scanning electron microscope (SEM).

\section{Test Results and Analysis}

\subsection{Effect of Amplitude on Microstructure of Gray Cast Iron}

3.1.1. Effect on Graphite Morphology. Figure 2 shows the graphite morphology of gray cast iron under different amplitude conditions. Among them, Figures 2(a)-2(d) are the graphite morphologies of gray cast iron prepared under the conditions of amplitude of $0,2,3$, and $4 \mathrm{~mm}$, respectively. It can be seen from the figure that when the amplitude is $0 \mathrm{~mm}$, there is a small amount of C-type block graphite in the gray cast iron, as shown by the arrow in Figure 2(a); with the increase in amplitude, the length and thickness of A-type flake graphite become shorter and thinner. Due to the effect of vibration in the solidification process of casting, the flow of metal melt is promoted, the temperature gradient of metal melt and the fluctuation of carbon atom concentration are reduced, which is conducive to the composition homogenization of metal melt, so that the nucleated flake graphite cannot grow up, and the graphite flake with shorter length and thinner thickness is formed [14].

Table 2 shows the statistical analysis results of graphite parameters in gray cast iron under four different amplitude conditions. It can be seen from Table 2 that the graphite content in gray cast iron first decreases, then increases, and then decreases with the increase in amplitude. When the amplitude is $2 \mathrm{~mm}$, the area ratio of graphite is the smallest, while when the amplitude is $3 \mathrm{~mm}$, the area ratio of graphite 


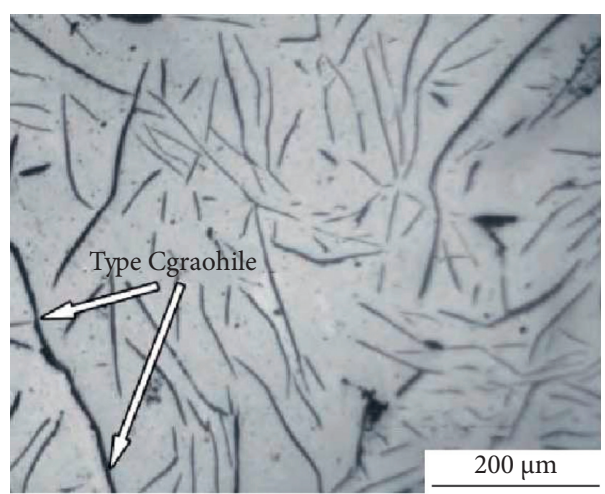

(a)

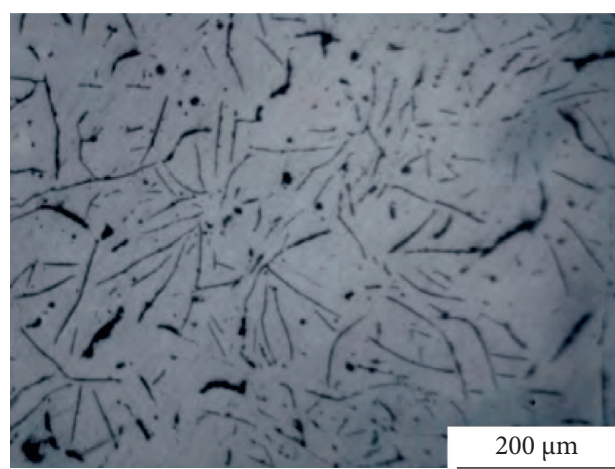

(c)

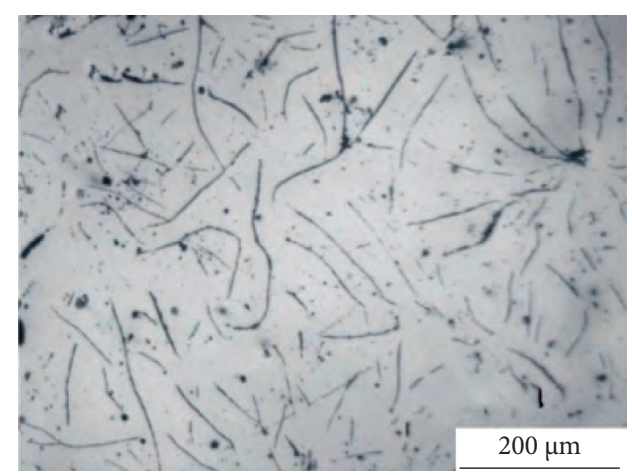

(b)

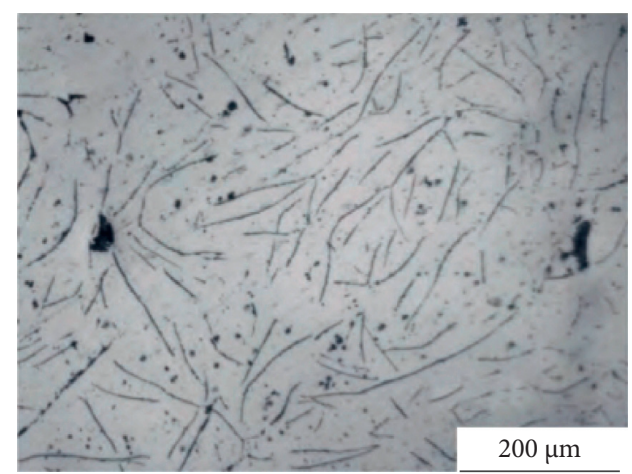

(d)

FIGURE 2: The influence of amplitude on graphite morphology in gray cast iron: (a) $0 \mathrm{~mm}$; (b) $2 \mathrm{~mm}$; (c) $3 \mathrm{~mm}$; (d) $4 \mathrm{~mm}$.

TABLE 2: Statistic of graphite parameter in gray cast iron with different amplitudes.

\begin{tabular}{lcccc}
\hline Amplitude (mm) & 0 & 2 & 3 & 4 \\
Graphite area ratio (\%) & 12.0 & 8.8 & 12.4 & 9.3 \\
Actual length of graphite (mm) & 0.37 & 0.32 & 1.20 & 0.36 \\
\hline
\end{tabular}

is the largest. In addition, comparing the actual length of graphite, the graphite length is the largest when the amplitude is $0 \mathrm{~mm}$, and the graphite length is the shortest when the amplitude is $3 \mathrm{~mm}$. As mentioned above, when the amplitude is applied in the process of gray cast iron by LFC, the length and thickness of flake graphite become shorter and reflected in the actual length of graphite that is the graphite is shorter when the amplitude is $2 \mathrm{~mm} \sim 4 \mathrm{~mm}$. In addition, the area ratio depends on the length and thickness of the graphite.

3.1.2. Effect on Primary Austenite of Gray Cast Iron. Figure 3 shows the primary austenite morphology of gray cast iron. Among them, Figures 3(a)-3(d) are the primary austenite morphologies of gray cast iron prepared under the conditions of amplitude of $0,2,3$, and $4 \mathrm{~mm}$, respectively.

It can be seen from Figure 3 that when the amplitude is $0 \mathrm{~mm}$, the austenite dendrite of gray cast iron in lost foam casting presents coarse columnar crystal. As shown by the arrow in Figure 3(a), besides columnar crystal, there are more fine cellular crystals with smaller grain size. When the amplitude is $2 \mathrm{~mm}$, there is no columnar crystal in austenite, and the cellular crystal in cast iron is more developed, and the grains branch from the core to the outside (Figure 3(b)). When the amplitude is further increased to $3 \mathrm{~mm}$, there are some undeveloped cellular crystals in gray cast iron (Figure 3(c)). When the amplitude is $4 \mathrm{~mm}$, the cellular grains are short and coarse, and no network skeleton structure is formed (Figure 3(d)).

The secondary dendrite of austenite precipitated in the solidification process of gray cast iron is broken under the combined action of motion resistance and inertia force, resulting in the decrease in austenite grain size and the formation of endogenous cellular crystal. For austenite dendrite in ideal state, there are three main forces in the process of vibration solidification: vibration induced exciting force, resistance of solidified crystal to viscous fluid motion, and inertial force under gravity. The resultant force of vibration induced exciting force and viscous resistance in one-dimensional vibration direction is the resistance of austenite dendrite motion. In the process of vibration solidification, the force acting on the root of austenite dendrite $\sigma_{\mathrm{Rf}}$ can be expressed as follows $[15,16]$ :

$$
\sigma_{\mathrm{Rf}}=\sigma_{\mathrm{ZU}(L)}+\sigma_{\alpha(L)}=\frac{24 \eta L^{2}}{D_{r}^{3}} V+\frac{4 \rho L^{2}}{D_{r}} \alpha .
$$

In equation (1), $\eta$ is the melt viscosity (N.S.m ${ }^{-2}$ ), $L$ is the vibration length of dendrite $(\mathrm{m}), D_{r}$ is the dendrite radius 


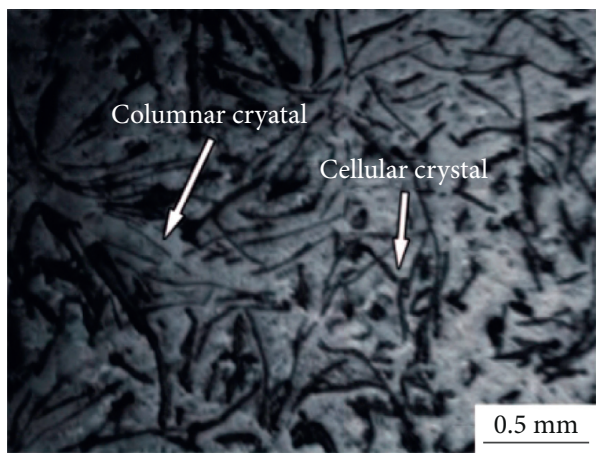

(a)

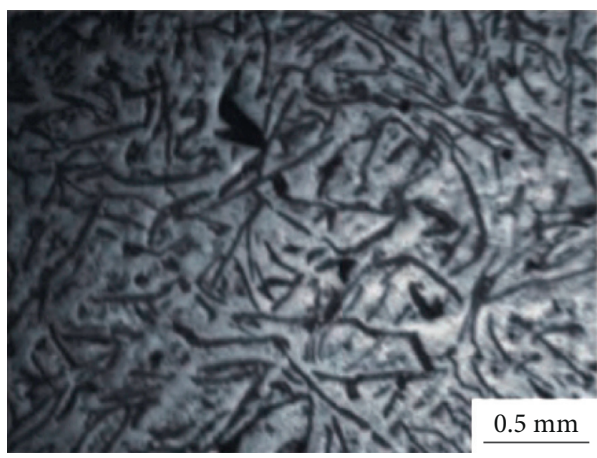

(c)

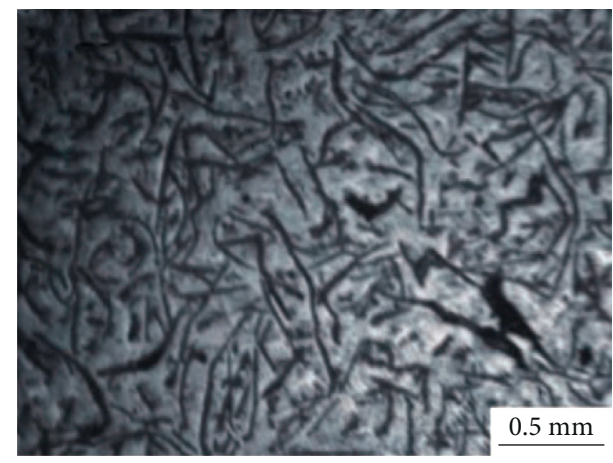

(b)

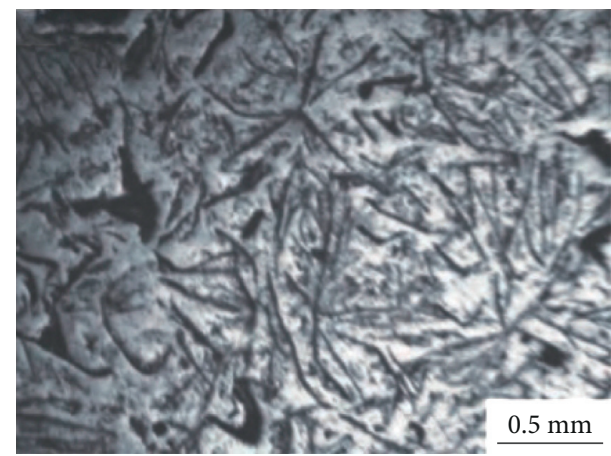

(d)

FIgURE 3: Effect of amplitude on morphology of primary austenite in gray cast iron: (a) $0 \mathrm{~mm}$; (b) $2 \mathrm{~mm}$; (c) $3 \mathrm{~mm}$; (d) $4 \mathrm{~mm}$.

(m), $V$ is the melt flow velocity $(\mathrm{m} / \mathrm{s}) ; \rho$ is the dendrite density $\left(\mathrm{kg} / \mathrm{m}^{3}\right) ; \alpha$ is the acceleration of dendrite movement $\left(\mathrm{m} / \mathrm{s}^{2}\right), \sigma_{\mathrm{Zu}(L)}$ is the viscous stress $(\mathrm{Pa})$, and $\sigma_{\alpha(L)}$ is the inertial stress $(\mathrm{Pa})$ in which $L$ can be understood as amplitude.

Assuming that the radius $\left(D_{r}\right)$ and density $(\rho)$ of the initial austenite dendrite are the same, it can be seen from formula (1) that when the amplitude increases, the resultant force on the root of the dendrite increases. Because the vibration makes the austenite dendrite refine and the radius of austenite dendrite decrease, when the austenite grain is refined, the resultant force of austenite dendrite increases, and the increase in resultant force caused by viscous stress is far greater than that caused by inertial stress, so the effect of fine grain increases, and finally the fine cellular crystal is formed. In addition, the researchers also found that during vibration solidification, the shrinkage defects in the casting decrease [17]. Due to the effect of inertial force on the metal melt, with the increase in amplitude, the inertial force increases, the shrinkage defects decrease, and the density increases.

In addition, the austenite structure in gray cast iron presents a more complex morphology. When the amplitude is $2 \mathrm{~mm}$, the austenite grains are smaller, while when the amplitude is larger, the austenite grains are coarser. This is mainly due to the remelting of the smaller secondary arm in the alloy. Under the action of mechanical vibration, the temperature gradient in the molten metal decreases and the difference of temperature field in the molten metal decreases, resulting in the lateral remelting of fine secondary dendrite arms, the increase in secondary arm spacing, and the increase in coarser branched dendrites and the coarsening of austenite [18, 19].

\subsubsection{Effect on Matrix Structure of Gray Cast Iron.} Figure 4 shows the matrix structure of gray cast iron. Among them, Figures $4(\mathrm{a})-4(\mathrm{~d})$ are the matrix structure diagrams of gray cast iron prepared under the condition of amplitude of $0,2,3$, and $4 \mathrm{~mm}$, respectively, and the vibration frequency is $35 \mathrm{~Hz}$.

It can be seen from Figure 4 that the matrix structure of gray cast iron prepared under different amplitude conditions is composed of pearlite and graphite. When the amplitude is $0 \mathrm{~mm}$, the flake carbide in pearlite in gray cast iron is larger, as shown by the arrow in Figure 4(a). Comparing the pearlite flake spacing of gray cast iron produced by several processes, it can be found that when the amplitude is $2 \mathrm{~mm}$, the pearlite flake spacing in gray cast iron is the largest, the cementite flake in pearlite is short and thick, and the cementite flake in pearlite has the tendency of granulation. When the amplitude is $0 \mathrm{~mm}$, the lamellar spacing of pearlite takes the second place, and there is a small amount of massive cementite in pearlite. When the amplitude is $3 \mathrm{~mm}$ and $4 \mathrm{~mm}$, the spacing of pearlite in gray cast iron decreases. When other conditions are the same, mechanical vibration is introduced in the solidification process of gray cast iron, which increases the solidification undercooling of gray cast iron and changes the morphological characteristics of pearlite in gray cast iron [20]. 


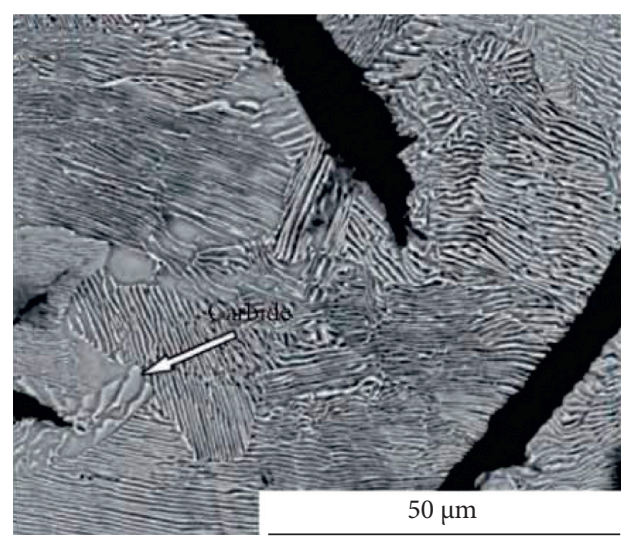

(a)

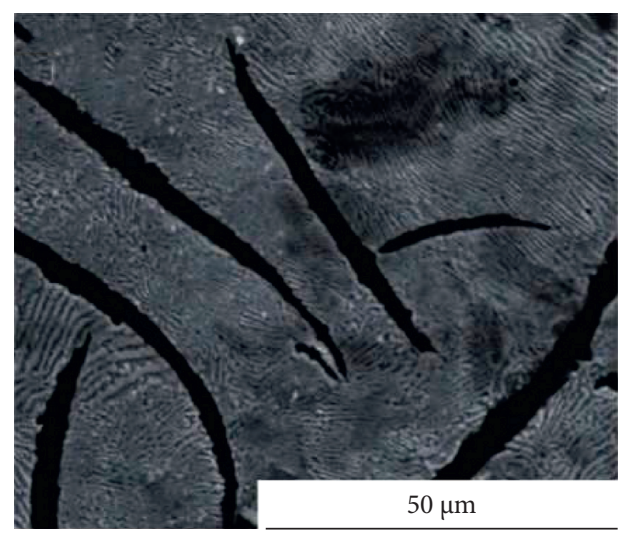

(c)

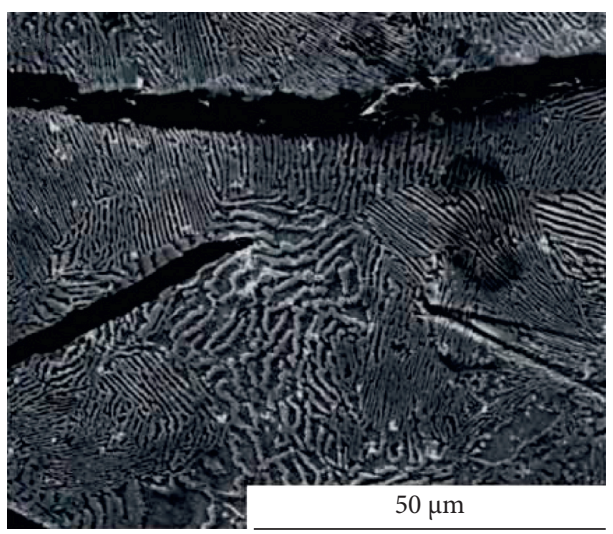

(b)

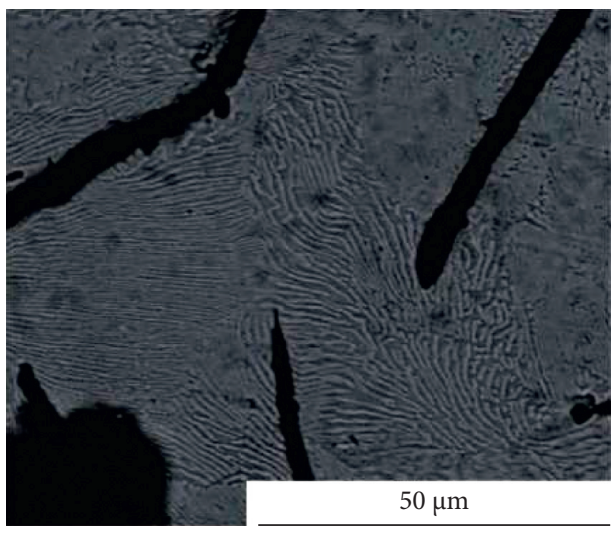

(d)

FIGURE 4: Effect of amplitude on microstructure of gray cast iron.

\subsection{Effect on Mechanical Properties of Gray Cast Iron}

3.2.1. Hardness. Table 3 show the change curve of Brinell hardness of gray cast iron with amplitude. It can be seen from Figure 5 that with the increase in amplitude, the Brinell hardness of gray cast iron first increases and then decreases. When the amplitude is $0 \mathrm{~mm}$, the Brinell hardness of gray cast iron is the smallest, and when the amplitude is $3 \mathrm{~mm}$, the Brinell hardness of gray cast iron is the largest. However, the Brinell hardness of gray cast iron prepared under the condition of amplitude of $2 \mathrm{~mm}$ and $4 \mathrm{~mm}$ has little difference.

The primary crystallization product of gray cast iron is austenite, which retains the original skeleton structure of austenite in the cast iron at room temperature and plays a strengthening role in the matrix of gray cast iron [21]. It can be inferred that the change trend of Brinell hardness of gray cast iron with the increase in amplitude is mainly related to the content and distribution of austenite structure in gray cast iron. Yüksel [22] considered that the Brinell hardness of gray cast iron is low due to the short and thick undeveloped equiaxed dendrite structure and the lack of frame structure. As can be seen from Figure 3(a), the columnar and cellular grains are separated from each other and do not form a continuous frame structure. Therefore, the Brinell hardness of gray cast iron is low. In addition, when the amplitude is $3 \mathrm{~mm}$, the cementite spacing of gray cast iron is small, which

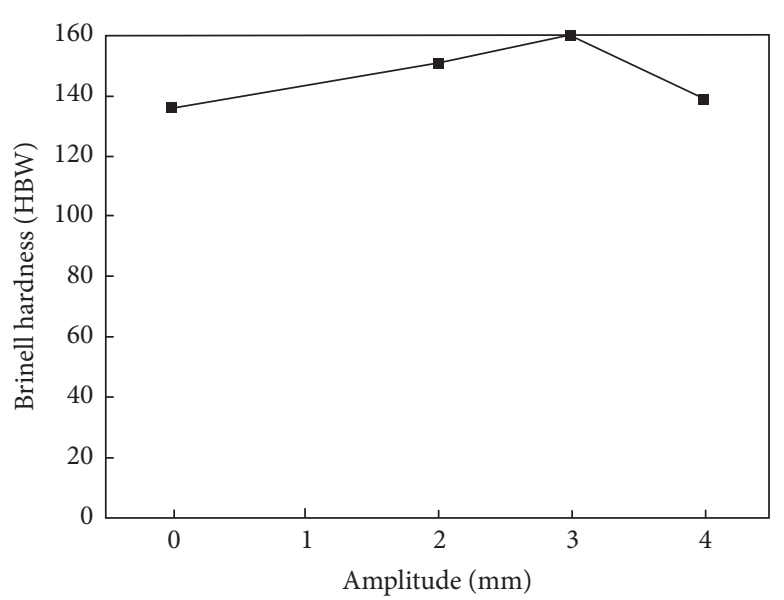

FIGURE 5: Effect of amplitude on Brinell hardness of gray cast iron.

makes the hardness of the alloy maximum, as shown in Figure 4(c).

3.2.2. Effect on Mechanical Properties. Table 4 show the curve of mechanical properties of gray cast iron changing with amplitude, and the vibration frequency is constant at $35 \mathrm{~Hz}$. It can be seen from Figure 6 that the tensile strength of gray cast iron increases first and then decreases with the 
TABLE 3: Effect of mechanical amplitude on the Brinell hardness of gray cast iron (HBW).

\begin{tabular}{lcccc}
\hline Amplitude $(\mathrm{mm})$ & \multicolumn{2}{c}{ Location } & Location 3 & 134.8 \\
& Location 1 & Location 2 & 133.8 & 148.7 \\
2 & 135.2 & 148.7 & 161.1 & 149.2 \\
3 & 150.2 & 160.4 & 135.6 & 159.8 \\
4 & 157.9 & 136.8 & 135.8 \\
\hline
\end{tabular}

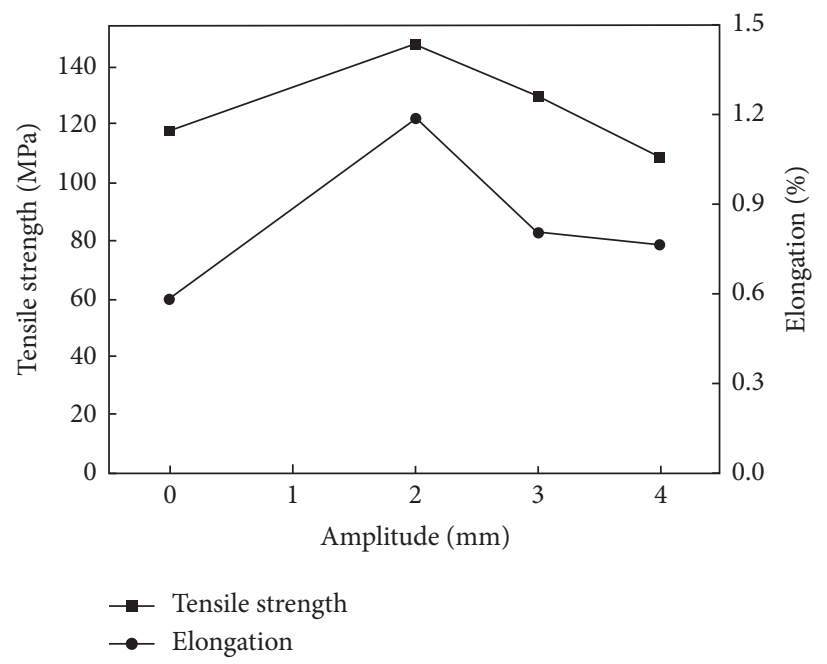

Figure 6: Effect of amplitude on tensile properties of gray cast iron.

TABLE 4: Effect of mechanical amplitude on the tensile properties of gray cast iron.

\begin{tabular}{lcccccccc}
\hline & \multicolumn{2}{c}{ Sample 1 } & \multicolumn{2}{c}{ Sample 2 } & \multicolumn{2}{c}{ Sample } \\
$\begin{array}{l}\text { Amplitude } \\
(\mathrm{mm})\end{array}$ & $\begin{array}{c}\text { Tensile } \\
\text { strength } \\
(\mathrm{MPa})\end{array}$ & $\begin{array}{c}\text { Elongation } \\
(\%)\end{array}$ & $\begin{array}{c}\text { Tensile } \\
\text { strength } \\
(\mathrm{MPa})\end{array}$ & $\begin{array}{c}\text { Elongation } \\
(\%)\end{array}$ & $\begin{array}{c}\text { Tensile } \\
\text { strength } \\
(\mathrm{MPa})\end{array}$ & $\begin{array}{c}\text { Elongation } \\
(\%)\end{array}$ & $\begin{array}{c}\text { Average } \\
\text { Tensile } \\
\text { strength } \\
(\mathrm{MPa})\end{array}$ & $\begin{array}{c}\text { Elongation } \\
(\%)\end{array}$ \\
\hline 0 & 117.3 & 0.65 & 115.8 & 0.60 & 116.4 & 0.61 & 116.5 & 0.62 \\
2 & 145.7 & 1.23 & 148.2 & 1.16 & 148.6 & 1.15 & 147.5 \\
3 & 128.9 & 0.77 & 132.1 & 0.81 & 129.6 & 0.79 & 130.2 \\
4 & 110.2 & 0.76 & 107.4 & 0.73 & 107.6 & 0.76 & 0.79 \\
\hline
\end{tabular}

increase in vibration amplitude. When the vibration amplitude is $2 \mathrm{~mm}$, the tensile strength of gray cast iron is the highest, with the value of $147.51 \mathrm{MPa}$. When the vibration frequency amplitude is $4 \mathrm{~mm}$, the tensile strength of gray cast iron is the lowest, with the value of $108.4 \mathrm{MPa}$. Compared with the gray cast iron with the amplitude of $2 \mathrm{~mm}$, the tensile strength is reduced by $26.51 \%$. The change trend of elongation of gray cast iron under different amplitudes is the same as that of tensile strength, but there is little difference in the elongation of gray cast iron with the amplitude of $3 \mathrm{~mm}$ and $4 \mathrm{~mm}$.

In gray cast iron, the main factors affecting its properties are austenite dendrite and graphite in gray cast iron [23]. It can be seen from the above analysis that when the amplitude is $2 \mathrm{~mm}$ and $3 \mathrm{~mm}$, the columnar crystal and cellular crystal have a greater hindrance to the deformation of the material, which makes the gray cast iron have higher tensile strength and elongation.

In addition, the graphite in gray cast iron is A-type flake graphite, which is equivalent to microcrack in the matrix structure, and it is easy to cause stress concentration at the sharp corner of graphite. When gray cast iron is under tensile action, the position of graphite flake is equivalent to cavity, which seriously splits the matrix, so the plasticity of gray cast iron is low. When the amplitude is different, the morphology, distribution, and content of graphite in gray cast iron are different, which is also one of the main reasons for the change of plasticity of gray cast iron.

Figure 7 shows the fracture morphology of gray cast iron under different amplitudes. Among them, Figures 7(a)-7(d) show the fracture morphology of gray cast iron made under the condition of amplitude of $0,2,3$, and $4 \mathrm{~mm}$, respectively. 


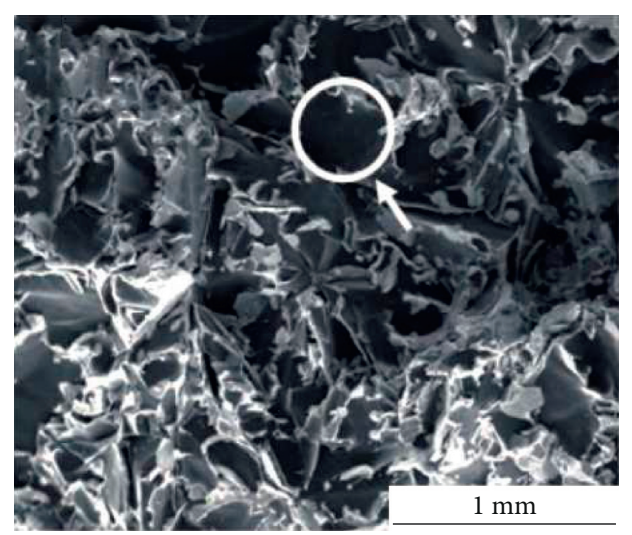

(a)

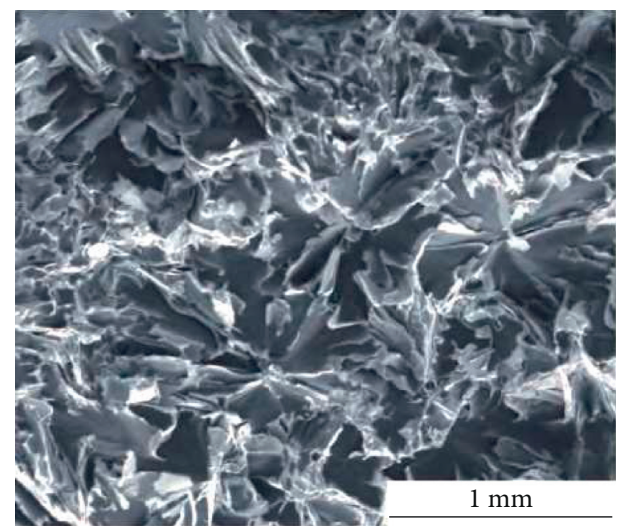

(c)

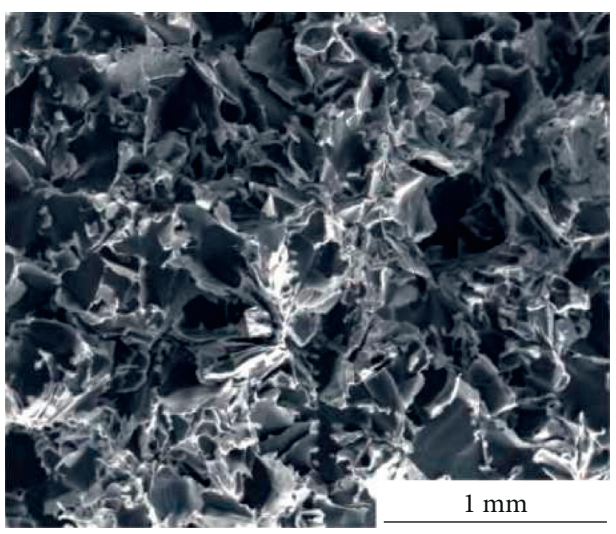

(b)

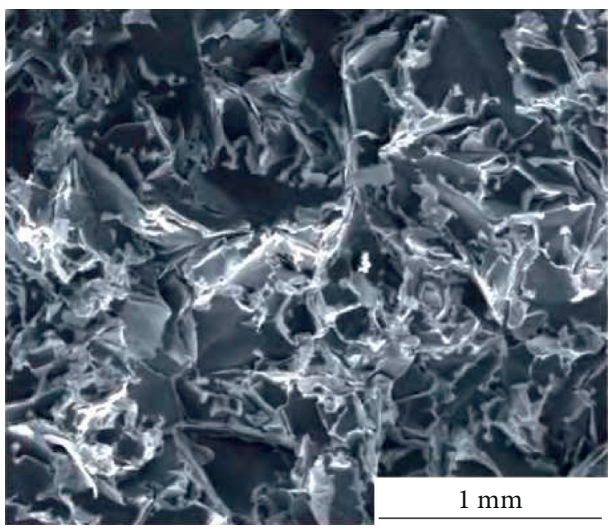

(d)

Figure 7: Effect of amplitude on fracture morphology of gray cast iron.

It can be seen from Figure 7 that the graphite on the fracture surface of gray cast iron is flower-like, and the fracture surface is mainly characterized by cleavage fracture of A-type flake graphite and matrix structure, with many holes distributed on the fracture surface. The existence of these holes reduces the tensile strength and elongation of gray cast iron. Comparing the size of holes on the fracture surface of gray cast iron made under different amplitude conditions, it can be found that when the amplitude is $0 \mathrm{~mm}$, the hole size is the largest, as shown in the circle area in Figure 7(a), so the elongation is the lowest. There are many dimples on the fracture surface of gray cast iron with the amplitude of $2 \mathrm{~mm}$, so the tensile strength and plasticity of gray cast iron are the highest. When the amplitude is further increased to $4 \mathrm{~mm}$, more holes appear on the fracture surface of gray cast iron, and the distribution of holes is relatively dispersed. Therefore, the tensile strength and elongation of gray cast iron are low.

\section{Conclusion}

(1) With the increase in amplitude, the amount of short and thin A-type flake graphite in gray iron increases, and the austenite structure transforms from columnar crystal to cellular crystal. Comparing the pearlite flake spacing of gray iron prepared under different amplitude conditions, it can be found that the flake cementite in pearlite of gray iron prepared with the amplitude of $2 \mathrm{~mm}$ coarsens, the flake spacing becomes larger, and the cementite has granulation trends.

(2) The hardness, tensile strength, and elongation of gray cast iron have the same change trend, which first increases and then decreases with the increase in amplitude. Mechanical vibration applied in the process of gray cast iron by lost foam casting is helpful to improve the hardness, tensile strength, and elongation after fracture of gray cast iron. The appropriate amplitude in the process of Y-shaped HT100 gray cast iron by lost foam casting is $2 \mathrm{~mm}$, while the tensile strength and elongation of gray cast iron are the highest, which are $147.51 \mathrm{MPa}$ and $1.28 \%$.

\section{Data Availability}

The raw/processed data required to reproduce these findings cannot be shared at this time as the data also form part of an ongoing study.

\section{Conflicts of Interest}

The authors declare that they have no conflicts of interest. 


\section{Acknowledgments}

This work was supported by the National Science and Technology Major Project (2017zx04011-012) and Special research plan fund of Shaanxi Provincial Education Department (15jk2183).

\section{References}

[1] M. Colak and S. Kaya, "Investigation of the effect of inoculant and casting temperature on fluidity properties in the production of spheroidal graphite cast iron," Transactions of the Indian Institute of Metals, vol. 74, no. 2, pp. 205-214, 2021.

[2] V. Chaturvedi and T. Talapaneni, "Effect of mechanical vibration and grain refiner on microstructure and mechanical properties of AZ91Mg alloy during solidification," Journal of Materials Engineering and Performance, vol. 3, pp. 1-16, 2021.

[3] S. Fan, H.-B. Wu, and J.-X. Fang, "Microstructure and mechanical properties of AZ91D magnesium alloy by expendable pattern shell casting with different mechanical vibration amplitudes and pouring temperatures," China Foundry, vol. 18 , no. 1 , pp. 1-8, 2021.

[4] B.-T. Xiao, Z.-T. Fan, W.-M. Jiang, X.-W. Liu, W. Long, and Q. Hu, "Microstructure and mechanical properties of ductile cast iron in lost foam casting with vibration," Journal of Iron and Steel Research International, vol. 21, no. 11, pp. 10491054, 2014.

[5] Y. X. Liu and B. X. Ma, "Effect of mechanical vibration amplitude on microstructure and properties of lost foam casting ZGMn13 steel," Hot Working Technology, vol. 47, no. 17 , pp. $85-87,2018$.

[6] G. Wu, S. Chen, and S. Zeng, "Effects of mechanical vibration on melting behaviour of phase change material during charging process," Applied Thermal Engineering, vol. 192, pp. 116914-116927, 2021.

[7] E. Cardoso-Legorreta, A. Arenas Flores, and F. L. García, "Effect of mechanical vibration during the solidification process of an aluminium alloy A356," Advanced Materials Research, vol. 976, pp. 14-18, 2014.

[8] B. T. Xiao, F. T. Zitian, and X. W. Liu, "Grain refinement and hafdness of grey cast iron in lost foam casting with mechanical vibration," Metalurgia International, vol. 16, no. 3, pp. 16-18, 2013.

[9] X. F. Tian, Z. T. Fan, and N. Y. Huang, "Effect of mechanical vibration on microstructure and mechanical properties of lost foam casting magnesium alloy," Chinese Journal of Nonferrous Metals, vol. 16, no. 11, pp. 1838-1844, 2006.

[10] W. Jiang, Z. Fan, X. Chen, B. Wang, and H. Wu, "Combined effects of mechanical vibration and wall thickness on microstructure and mechanical properties of A356 aluminum alloy produced by expendable pattern shell casting," Materials Science and Engineering: A, vol. 619, no. 12, pp. 228-237, 2014.

[11] Z. Zhao, Z. T. Fan, P. Chen, B. Tang, and D. Pan, "Semi-solid isothermal heat treatment of $\mathrm{AlSi}_{7} \mathrm{Mg}$ alloy with vibration in lost foam casting," Heat Treatment of Metals, vol. 35, no. 1, pp. 58-62, 2010.

[12] B. T. Xiao, Z. T. Fan, W.-M. Jiang, X.-W. Liu, W. Long, and $\mathrm{Q} . \mathrm{Hu}$, "Microstructure and mechanical properties of ductile cast iron in lost foam casting with vibration," Journal of Iron and Steel Research, International, vol. 21, no. 11, pp. 10491054, 2014.

[13] A. Kisasoz, K. A. Guler, and A. Karaaslan, "Influence of orbital shaking on microstructure and mechanical properties of A380 aluminium alloy produced by lost foam casting," Russian
Journal of Non-Ferrous Metals, vol. 58, no. 3, pp. 238-243, 2017.

[14] R. K. Tayal, S. Kumar, A. Mondal, and S. Jambhale, "Experimental investigation and parametric optimization of AA6063/AA6351 alloys bimetallic prepared by vacuumassisted lost foam compound casting process," International Journal of Metalcasting, vol. 14, no. 1, pp. 243-256, 2020.

[15] P.-M. Geffroy, M. Lakehal, J. Goñi, E. Beaugnon, and J.-F. Silvain, "Thermal and mechanical behaviour of grey cast iron and ductile iron castings using magnetic molding and lost foam processes," Journal of Materials Processing Technology, vol. 209, no. 8, pp. 4103-4111, 2009.

[16] S. O. Seidu, "Effect of compositional changes on the mechanical behaviour of grey cast iron," Journal of Metallurgical Engineering, vol. 3, no. 2, pp. 92-95, 2014.

[17] W. Sun, H. E. Littleton, and C. E. Bates, "Formation mechanism of gas cavity defects in lost foam iron castings," International Journal of Cast Metals Research, vol. 16, no. 6, pp. 549-553, 2016.

[18] B. T. Xiao, Z. T. Fan, W. M. Jiang, J.-H. Xiang, and X.-F. Yan, "Effect of vibration frequency on primary phase and properties of grey cast iron fabricated by lost foam casting," China Foundry, vol. 17, no. 1, pp. 7-13, 2020.

[19] S. P. S. Singh Sivam, A. Rajasekaran, S. Rajendrakumar, K. SathiyaMoorthy, and M. Gopal, "A study of cooling time, copper reduction and effects of alloying elements on the microstructure and mechanical properties of SG iron casting during machining," Australian Journal of Mechanical Engineering, vol. 19, no. 1, pp. 10-18, 2021.

[20] T. Um, S. K. Wilke, H. Choe, and D. C. Dunand, "Effects of pore morphology on the cyclical oxidation/reduction of iron foams created via camphene-based freeze casting," Journal of Alloys and Compounds, vol. 845, pp. 156278-156280, 2020.

[21] H. F. Cheng, Z. J. Hu, M. G. Xie, H.-C. Sun, H. Jin, and W. Liu, "Influence of sulfur on microstructure and properties of gray cast iron by LFC," Foundry, vol. 60, no. 1, pp. 62-65, 2011.

[22] A. Yüksel, "Microstructural analysis of EN-GJS-450-10 ductile cast iron via vibrational casting," China Foundry, vol. 17, no. 4, pp. 272-278, 2020.

[23] K. Davut, A. Yalcin, and B. Cetin, "Multiscale microstructural analysis of austempered ductile iron castings," Microscopy and Microanalysis, vol. 23, no. S1, pp. 350-351, 2017. 